\title{
El reino de dios entre nosotros o los anteojos de la historia. Conversación con Artur Becker.
}

\author{
Jesús Sepúlveda \\ University of Oregon \\ jsepulve@uoregon.edu
}

66 ottes Reich Unter Uns" reza una de las inscripciones en las estelas del parque Sachsenhain en las afueras de la ciudad de Verden en el norte de Alemania. Las estelas forman parte de un conjunto de rocas que demarcan el parque, simulando senderos que en un principio debían figurar la cruz gamada. Las sendas están bordeadas por árboles y arbustos que alguna vez fueron plantados como tributo a la antigua religión alemana: el paganismo. En total hay 4500 rocas de granito. Cada una de ellas conmemora a uno de los 4500 sajones masacrados por Carlomagno en el año 782 E.C.

Fue durante una campaña populista de rescate de las raíces pre-cristianas del Tercer Reich que los vecinos enviaron desde cada ciudad alemana una 
roca como aporte a la construcción del memorial. Su construcción estuvo a cargo de Heimrich Himmler, el omnipotente jefe de la SS, quien vio en la arboleda de Sachsenhain las bases épicas para la fundación ideológica del nacionalsocialismo. El propio Himmler inauguró el sitio. Y para ello eligió como fecha emblemática el solsticio de verano. Era el año 1935 y el esoterismo le daba la mano al militarismo para dar los primeros pasos de esa danza asesina que se llamó Segunda Guerra mundial.

Alfred Rosenberg, ideólogo y fundador de la teoría de la pirámide racial, pronunció el discurso inaugural. Sin hacer paralelismos, habló de la crueldad de los métodos cristianos de conversión, condoliéndose de los paganos masacrados. Y así como los navarros acusados de brujería por el Santo Oficio fueron obligados a portar una estrella verde durante el siglo XVII, los judíos se vieron forzados a portar una estrella amarilla en el horroroso siglo XX. Quizás la llamada "solución final" no solo fuera una política de exterminio sistemático, sino también una parodia de la tragedia histórica.

Seguramente fue por su belleza natural que Sachsenhain se transformó rápidamente en un centro de vacaciones y adoctrinamiento para la Juventud Nazi. Para el término del último lustro de la década del treinta, el nazismo ya se había desprendido de todo esoterismo pagano, comenzando a instrumentalizar el cristianismo y a apropiarse de la figura de Carlomagno. Por ello se hizo hincapié en su entronización como emperador de Europa en el año 800 E.C. Su figura representaba -y quizás lo siga haciendo- el origen genealógico de la fundación cristiana de Occidente, al mismo tiempo que auto legitimaba el nazismo como heredero de un proyecto civilizatorio de expansión, que abarcaba desde el control territorial hasta la experimentación genética. Karl der Große fue uno de los mitos fundacionales del nacionalsocialismo, cuya máquina ideológica orientada a garantizar "el reino de dios" entre sus descendientes no podía sino discriminar, excluir y asesinar a los que no formaran parte de su rebaño. Y si esto fue cierto para los nazis, como lo fue para la Contrarreforma 


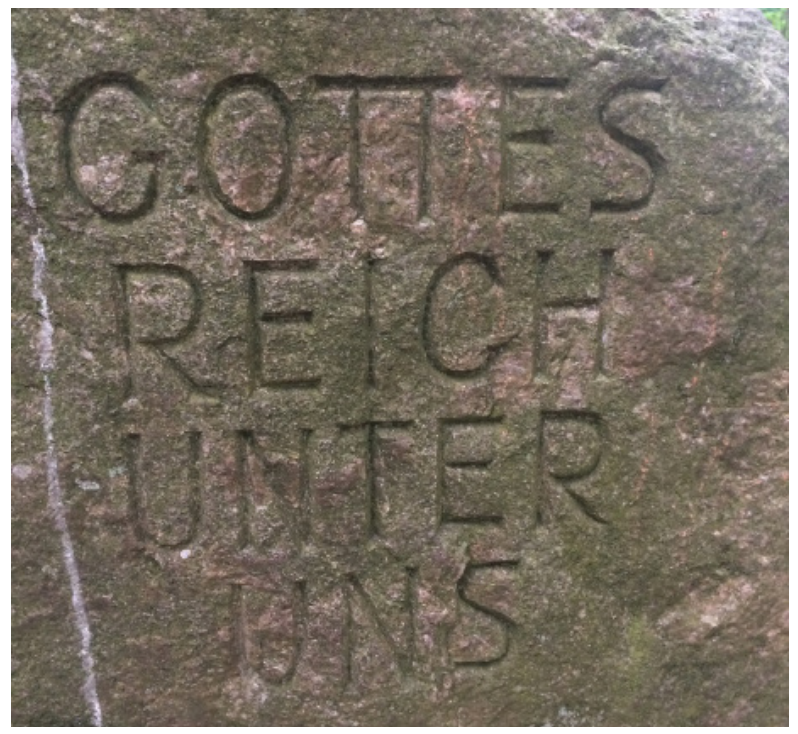

española, también lo es hoy para el imperio occidental norteamericano, el fundamentalismo religioso, el sionismo y todo lazo de fascismo populista y evangelismo intolerante incubado en el huevo de la serpiente. Pensar que haya dos rebaños, el de dios y el de los enemigos de dios, abre las compuertas del infierno. No hay nada divino en la idea de un dios que se transforma en una empresa bélica y privada: "Gottes Reich Unter Uns" -el reino de dios entre nosotros (y no para ellos).

Finalizada la guerra, muchos alemanes -en su proceso de expiaciónpropusieron destruir el parque. Hubo voces que, sin embargo, se opusieron, argumentando que había que mantenerlo como una suerte de museo de la memoria. Y no se equivocaron.

Hoy por hoy, el sitio está administrado por una iglesia evangélica que lo mantiene para profesar la fe luterana. Curioso: aunque las creencias sean efímeras, la energía de los lugares permanece. 
Sachsenhain es, sin lugar a dudas, uno de esos lugares del planeta donde confluyen fuerzas geológicas cuyo magnetismo es palpable a flor de piel. Por allí caminé con el poeta Artur Becker, quien me explicó en detalle el significado histórico de este sitio, estableciendo paralelismos entre la Alemania nazi y el régimen soviético de Polonia. De paso, hablamos del horror de la dictadura chilena. También intercambiamos ideas y percepciones sobre el arte de la palabra. Y concordamos que la poesía no es solo lenguaje, sino también un modo de vida: una forma de ser y sentir.

Conocí a Artur en diciembre de 2017 en Santiago de Chile. Invitado por la Fundación Sylt, Artur cumplía una residencia en un barrio colindante al río Mapocho, mientras se enteraba de la rica tradición poética chilena, conociendo a escritores y apuntando nombres para luego leer y traducir. Admirador de Czesław Miłosz, Artur también es una de esas rarezas biculturales que alternan dos idiomas como lenguas literarias. En su caso: el polaco y el alemán.

No sé si fue en Santiago, en una conversación propiciada por la curadora y crítica de arte Indra Wussow, o luego en Verden, "ese tipo de suburbio de Bremen", a decir del propio Artur, que me enteré de Sachsenhain. El parque, próximo al río Aller, cuyo significado de "totalidad" fue simbólico para la psicología vernacular, fue un centro de operaciones durante la Segunda Guerra mundial. Testigo de los rituales nocturnos de la Juventud Nazi, Hitler aleonaba a sus huestes al compás de los tambores y el fuego de las antorchas, dejando en claro que el nazismo no solo fue -y es- una ideología sino también "una suerte de religión artificial y asesina”, tal como lo caracteriza Becker. Pero ¿qué ideología no ha manchado con sangre los muros de sus instituciones y qué religión no ha alimentado el monstruo que supone superiores a unos sobre otros? Cuando hay colusión entre el populismo y las instituciones religiosas, las masas enarbolan caudillos todopoderosos, cuyos totalitarismos suelen ser cruentos y fatales.

Pero Sachsenhain es también un lugar de caminata, un lugar para pasear 
con los amigos y conversar. Allí también, según Becker, "se hace visible la historia de Alemania" y se divaga sobre poesía: esa condición del espíritu que hace que unos se pongan bravos con el poder, las instituciones y toda suerte de autoritarismos.

Allí acordamos con Artur la siguiente conversación (electrónica), que poco a poco he ido traduciendo. Quizás lo que siga pueda, en cierto modo, aluzar al lector hispanohablante sobre el pensamiento de este multifacético escritor polaco-alemán nacido en la región eslava de Masuria hace 50 años. Quizás también haya que decir que Artur Becker es poeta, novelista y ensayista, autor de una veintena de libros, entre los que destaca la antología Ein Kiosk mit elf Millionenn Nächten [Un quiosco con once millones de noches] publicada en 2008 y el libro de ensayos Kosmopolen. Auf der Suche nach einem europäischen Zuhause [Kosmopolen. En busca de un hogar europeo] publicado en 2016. O quizás no haya que decir nada y dejar simplemente que la conversación fluya como vertiente de valle entre las montañas.

Sepúlveda: Estimado Artur: hemos hablado de la energía poética, que se siente o no se canaliza, su vibración vital, pero también de su cuerpo en tanto palabra y significado. En este sentido, cuéntanos cómo empezaste a escribir y qué influencias literarias -y vitalesreconoces. ¿Cómo fue el proceso de tu formación? ¿Ves acaso en las imperfecciones de la realidad, a decir de Adorno, algún tipo de motivación poética?

Becker: Vengo de un país en el que el principal género literario es la poesía, incluso más importante que la novelística. La figura del poeta polaco es principalmente la de un autor de poemas y ensayos y, ocasionalmente, de prosa: novelas y cuentos. También es un traductor. Publiqué mis primeros poemas en Polonia cuando 


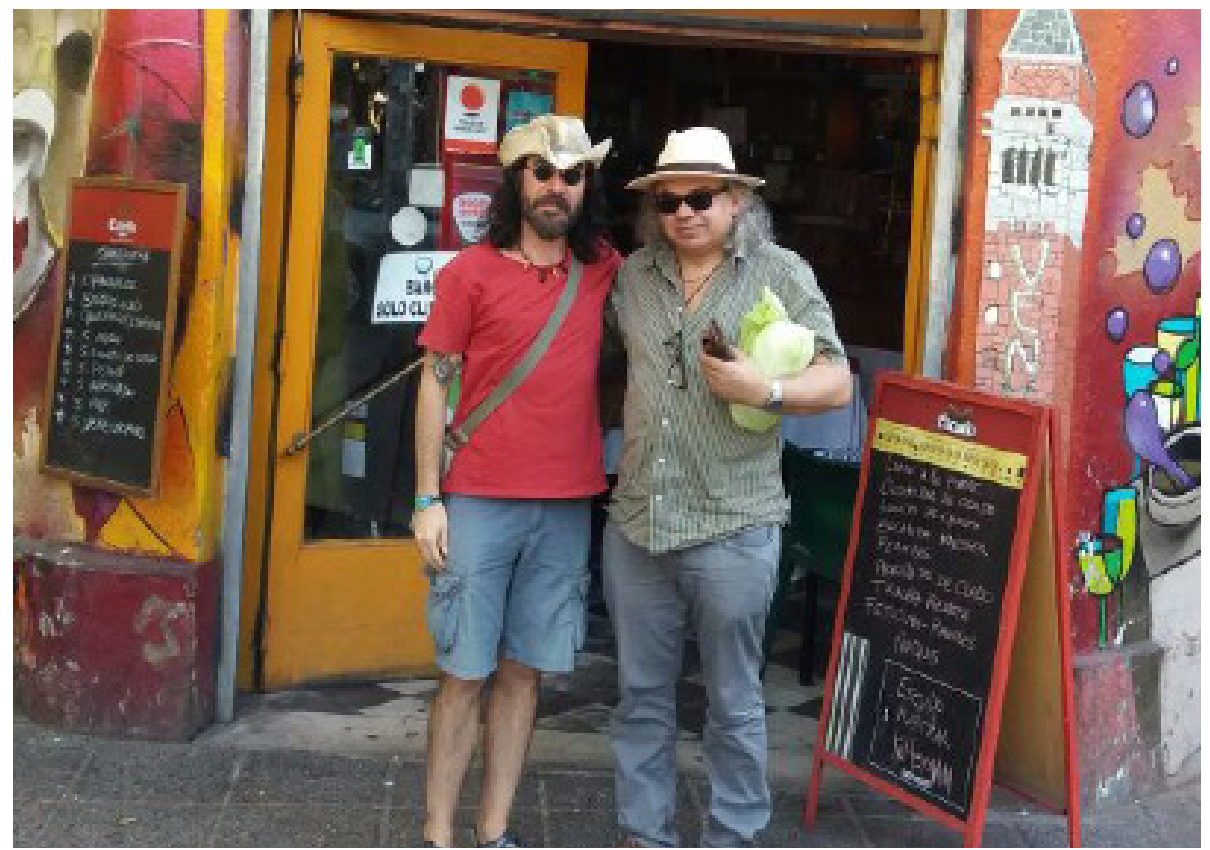

tenía 15 años. Hoy en día, las personas piensan que establecer conexiones con otros poetas, revistas y periódicos es muy bueno. Aquello fue entre 1983 y 1987 en pleno socialismo. Fui también afortunado de que mi madre fuera profesora de polaco y que a menudo invitara poetas a su escuela. Estaba, por decirlo de algún modo, bien "conectada". Además amaba la poesía y a los poetas. Recuerdo que una vez un escritor mayor me envío una postal que decía: "Si quieres ser poeta, debes leer y escribir mucho". Por supuesto, tomé aquel consejo al pie de la letra. En mi formación hubo además coincidencias maravillosas: la casa donde crecí era un típico edificio de concreto en el que también vivía una mujer estalinista, a quien describo treinta años más tarde en mi novela de iniciación: Der Lippenstift meiner Mutter [El lápiz labial de mi 
madre] (2010). La mujer escribía poemas patéticos sobre nuestra pequeña y rancia ciudad llamada Bartoszyce. Pero ella fue mi primera editora y adoraba mi poesía moderna. Además, mi madre tenía una biblioteca personal considerable: Czesław Miłosz, Tadeusz Różewicz, Konstanty Ildefons Gałczyński, Thomas Mann, Alberto Moravia, Albert Camus, y Shakespeare. Rápidamente leí sus libros. Inmediatamente compredí que entendía mejor el mundo de la literatura que la llamada realidad exterior. Al mismo tiempo, con solo 15 años, me enamoré de una muchacha junto a un lago sobre quien escribí más tarde, además de poemas, la novela Wodka und Messer. Lied vom Ertrinken [Vodka y cuchillo. Canción de ahogo] (2008). Los primeros poemas que escribí eran poemas de amor dedicados a Magdalena, con quien permanezco hasta hoy tal como lo hizo Nabokov con su Vera. Pero mi mayor fortuna fue publicar poemas siendo adolescente y ser invitado a encuentros de poesía. Entonces era ingenuo y estúpido y no me había dado cuenta de que el trabajo de un escritor es estudiar la realidad tal como lo hace un físico. Al comienzo, no sabía lo que era la poesía. Solo fluía en el papel de una manera exaltada. No sabía que la poesía es ante todo un trabajo agotador y muy peligroso porque como poeta uno desarticula el espacio y el tiempo como un reloj para luego volver a ensamblarlo. Lo que quiero decir es que la principal razón para escribir fue que sabía que algo no estaba bien en el mundo, la realidad y la gente. Todo parecía un drama sin fin, una comedia. Esto probablemente es porque crecí en un país católico y socialista, que era un régimen tanto comunista como religioso. La naturaleza también cumplió un rol fundamental en mí: crecí en Masuria, en la antigua Prusia Oriental, que hoy es territorio polaco. Esta región está Ilena 
de lagos, bosques, estrellas y animales. El realismo mágico de la provincia, la naturaleza maniquea y su territorio fronterizo también jugaron un rol importante. Además, esta frontera europea es muy importante por su historia cultural: Immanuel Kant, Hannah Arendt, Johann Gottfried Herder, y Siegfried Lenz vienen de mi terruño natal. ¡La ilustración!

Sepúlveda: Cuéntanos, ¿cuál es tu impresión de la poesía alemana y polaca actual? ¿Cómo evalúas esta poesía en el contexto poético europeo de los siglos XX y XXI?

Becker: Ambos países, Alemania y Polonia, son muy responsables con su poesía. Alemania produjo a Gottfried Benn y Bertold Brecht en el siglo XX; pero la segunda mitad de esta centuria asesina pertenece a los polacos: Czesław Miłosz (Premio Nobel en 1980), Tadeusz Różewicz, Zbigniew Herbert y Wisława Szymborska (Premio Nobel en 1996), quienes establecieron la famosa "escuela polaca". En general, en Europa, y no solo en Polonia, somos muy afortunados de que Czesław Miłosz haya nacido y se haya hecho poeta. Él fue uno de los grandes poetas del siglo XX, junto a T. S. Eliot y Constantino Cavafis. Pero todo este legado es enorme y difícil y, ciertamente, Adam Zagajewski fue capaz de asumir tal legado y desarrollarlo luego en la poesía polaca: la llamada “escuela polaca". En los años 80 y 90 la nueva poesía polaca abrió nuevos caminos: lo personal y lo fenomenológico conquistaron la esfera de lo poético, tal como se puede apreciar en los poemas de Jacek Podsiadło. Frank O’Hara fue revivido en Polonia. Hay que agregar a esto la transformación de 1989, cuando los poetas polacos escribieron sobre la nueva realidad capitalista. Pero en 
la reducción del yo lírico a la privacidad, el poeta ha funcionado durante mucho tiempo. Desde hace unos pocos años, la poesía polaca ha vuelto a una nueva dirección, especialmente con la poesía femenina, que tiene una larga tradición en Polonia. Al menos todo el mundo conoce a Szymborska y Julia Hartwig, y también a María Pawlikowska-Jasnorzewska. La poesía polaca de hoy es probablemente la más temática y estilística de Europa en lo que respecta al procesamiento del relato histórico y privado. Eugeniusz Tkaczyszyn-Dycki escribe salmos barrocos sobre la gente de su tierra natal en la zona fronteriza de Polonia y Ucrania. Tomasz Różycki, proveniente de una antigua ciudad alemana llamada Opole [hoy en el sur de Polonia], es un poeta educado e intelectual que, exactamente como Tkaczyszyn-Dycki, habla de su infancia en el contexto de la historia de su país. Pero la poesía de Różycki no es barroca; al contrario, cautiva con su riqueza inventiva de imágenes y su estilo de escritura claro y sofisticado. Julia Fiedorczuk fue galardonada este año con el Premio de Poesía Wisława Szymborska. Ella elabora un discurso sobre el mundo, escribiendo poemas de días y épocas pasadas. Si uno compara la poesía lírica moderna polaca con la alemana, se nota que la poesía lírica alemana después de 1989 ha sido muy homogénea durante muchos años, estando ocupada consigo misma y, por lo tanto, de difícil acceso para los extranjeros, aunque Adam Zagajewski haya hecho una gran carrera internacional. Además, los alemanes estuvieron ocupados durante mucho tiempo con su unificación en 1990 y los poetas de Alemania Oriental, tal como Kurt Drawert, tuvieron una experiencia muy distinta de la historia occidental de su país, trayendo una metafísica y ontología muy diferente a la de los poetas de Alemania Occidental. Hoy en 
día, la poesía alemana moderna es mucho más cosmopolita y accesible para los extranjeros, como se puede ver en el ejemplo de la poesía de Jang Wagner, Norbert Hummelt o Monika Rinck. La educación juega un papel importante, al igual que la cultura pop, pero la poesía alemana moderna, como la polaca, busca un enfoque ontológico. Esta es ciertamente una característica común porque se trata de la cuestión de la calidad de nuestra existencia humana y nuestra realidad. Estoy principalmente interesado en temas filosófico-teológicos antes que nada.

Sepúlveda: Sé que admiras a Czesław Miłosz. ¿Qué papel ha jugado él en tu formación como escritor? ¿Qué nos puedes decir de tu amor por su poesía?

Becker: La poesía polaca tiene una larga tradicón de inmigración. Para mí, que salí de Polonia a la edad de 17 años en 1985, la búsqueda de modelos a seguir fue relativamente fácil porque estaba interesado en los poetas polacos del cículo de inmigrantes de París que publicaban la revista Kultura. No solo Miłosz era uno de los poetas de Kultura sino que también el antipoeta y anti-lírico Witold Gombrowicz, quien es bastante conocido en América Latina. El país de la infancia de Miłosz en Lituania y su mitología de "Paraíso Perdido" me recuerda mi propio lugar de origen en los límites de Masuria. Su novela Valle de Issa habla universalmente del antiguo mito del Jardín del Edén y de la expulsión. Pero lo que más me atrajo hacia él fueron sus poemas, que son filosóficos, enigmáticos, teológicos, sabios y "catastróficos". Y Miłosz estaba constantemente buscando una forma perfecta, que él llamaba "forma con mayor plenitud". Un poema nunca debiera ser reducido a su función y gesto poético y estilístico. Un poema 
debiera ser también un estudio ontológico y metafísico de la realidad y del presente eterno. $Y$ específicamente debe estar anclado en nuestra historia; esto es, en nuestra historia cultural, religiosa, filosófica, privada. Los problemas reales en el socialismo y la confrontación con Hegel y la gnosis, la teosofía y la religion fueron sus temas: ¿Qué otro poeta tiene tal rango temático? Todo el mundo debiera leer su ensayo "El país Ulro", que se considera un poema. Por sobre todo, Miłosz estaba preocupdo del conflicto entre el racionalismo exagerado (positivismo, cientificismo) y el romanticismo profético (idealización). Fue, en su opinión, el énfasis desmedido de lo racional lo que ha conducido a muchos conflictos. Miłosz no solo fue un enemigo declarado del frío entendimiento de la poesía de William Blake o de la gran poesía nacional de Adam Mickiewicz. Este poeta polaco y Nobel de literatura, nacido en 1911, experimentó en forma personal -a través del nacionalsocialismo y el comunismo estalinista- lo que la mente es capaz de hacer si el ser humano se reduce a un puro y crudo material histórico. No por nada Miłosz fue amigo de Albert Camus, quien lo defendió en Francia en 1951, cuando el poeta polaco partió al exilio. Neruda y Sartre consideraron a Miłosz un traidor de la causa socialista (izquierdista). Creo que lo que me intriga de Miłosz es su falta de unidad entre Occidente y Oriente, entre la izquierda y los conservadores, entre la ilustración y el romanticismo, entre el amor a la vida y la tristeza porque todo es pasajero. No conozco a ningún otro poeta que, además de escribir poemas filosóficos en los que aparecen Swedenborg o Descartes, escribiera maravillosos poemas sobre los pequeños goces de la vida tal como en su poema "El regalo". En fin, me encanta Miłosz porque escribió y pensó en forma holística, global, cósmica y, al 
mismo tiempo, realista. En su trabajo el poema nunca es escrito con un propósito personal.

Sepúlveda: Siendo originario de Polonia, llevas más de 30 años viviendo en Alemania. ¿Cómo afecta esto tu modo de escribir y tu identidad literaria? ¿Te sientas un poeta alemán que además escribe en polaco, o un escritor polaco que escribe en su segundo idioma? ¿Cómo enfrentas el bilingüismo y la escritura? ¿Dónde terminan, comienzan o se deshacen las fronteras?

Becker: $\quad$ Hoy en día ser un hablante y un poeta en un idioma nativo no es suficiente. Después de todo, todos somos refugiados y la movilidad de nuestro tiempo será incluso mayor y más poderosa. Aprendí alemán a los 17 años, pero el descubrimiento más maravilloso para mí fue que me di cuenta de que el alemán es tan poético y tan flexible como mi polaco natal. En una entrevista dije algo irónico y provocador respecto a la locura que es la literatura nacional. Dejé de escribir en polaco en 1989. Desde entonces he publicado en Alemania alrededor de 20 libros. Pero en 2015 mi añoranza por el idioma polaco despertó repentinamente y comencé a escribir de nuevo poemas en polaco, además de ensayos para los periódicos más importantes de Polonia, el Rzeczpospolita y la Gaceta Wyborcza. Y ahora escribo en dos idiomas y me maravillo que no haya conflicto. De igual modo publicaré mi próximo poemario -escrito en alemán en Polonia, que he traducido al polaco. Este doble trabajo es cansador, pero después de que escribo un poema en polaco, ansío tenerlo inmediatamente en alemán. Me encanta escribir novelas en alemán. El idioma alemán -con su larga tradición poético-filosófica (del idealismo alemán a 
Nietzsche y Rilke) es increíblemente vívido, pero también muy concreto y estricto, ideal para contar historias. Pero no quiero hacer generalizaciones. Solo un tonto las haría. A través del cambio de idiomas, he desarrollado un enorme respeto por otros idiomas y culturas y reverencio toda poesía, incluyendo la chilena o mexicana. Me he dado cuenta cuán frágil son nuestros idiomas. La poesía no es esclava de los idiomas. Ella se siente en casa en cualquier idioma. Uno solo tiene que capturarla. Ella es libre.

Sepúlveda: En diciembre de 2017 tú estuviste en Chile invitado por la Fundación Sylt como escritor en residencia. ¿Cuál fue tu impresión de Chile? ¿Confirmó acaso esta visita lo que alguna vez Gastón Salvatore te informara en las conversaciones que mantuviste con él? ¿Qué paralelos hay entre la historia reciente de Chile, Alemania y Polonia?

Becker: Chile me recuerda mucho a Polonia, especialmente por las transformaciones de ambos países en los años 1989-1990, que me parecen similares en muchos sentidos. Nuestro general Jaruzelski no fue tan sanguinario como Pinochet y además era comunista. Por lo mismo, puedo entender la transaformación social de Chile muy bien. Tampoco me molesta haber encontrado amigos chilenos que consideren el comunismo de manera tan ingenua porque nunca han experimentado el socialismo real. El comunismo polaco fue un régimen, un sistema criminal que todos sufrimos tanto en el plano humano, estético, legal, judicial como libertario. Por ello me fascinaron tanto las diferencias que hay en cómo definimos la izquierda y la derecha. Por supuesto, en Chile también se ha leído a Didier Eribon, Michel Foucault o Zygmunt Bauman, quien no 
solo era socialista sino también freudiano. Pero en Chile, como en Polonia y Alemania, todavía tenemos una visión muy diferente de la historia de nuestros países, de Europa, de América, etcétera. Me sorprendió, sin embargo, lo similar de nuestra mentalidad, de algún modo europea, polaca, alemana, chilena, (post) postcolonial, global, o sea, humana y poetológicamente similar. Esto quizás se relacione al hecho de que los chilenos, como los polacos y los alemanes, sean también transgresores fronterizos, geopolítica y culturalmente hablando. De todos modos, Chile me parece increíblemente vivo y abierto. Ese es un aspecto. El otro es, por supuesto, más complicado. Como Alemania y Polonia, Chile tiene mucho que mordisquear y sufrir cuando trata de lidiar con su propia historia. Algunos cierran sus ojos. Otros no pueden olvidar. Tal proceso llevará mucho tiempo. Lo sé por experiencia propia al haber vivido los procesos de Alemania y Polonia y visto tanto a perpetradores y víctimas. Esta es la razón por la cual fue tan importante para mí venir a Chile y estudiarlo cuidadosamente. La curadora de la Fundación Sylt, residente en Johannesburgo, Indra Wussow, hizo posible este viaje. Y estoy muy agradecido de ella, especialmente porque a través de ella te conocí a ti, a Enrique Winter, a Rodrigo Naranjo y a Carmen Berenguer. También he escrito poemas y ensayos sobre estos encuentros en Alemania y Polonia y los he publicado en ambos países. Soy, en general, una persona de pensamiento optimista, aunque los filósofos digan que los optimistas son unos idiotas, igual que los pesimistas. He visto, sin embargo, un Chile maravilloso; y no solo los tanques de Pinochet, las tres casonas de Neruda o los clásicos errores de la economía socialista de Allende o del neoliberalismo económico. Eso es solo parte de la historia. También busqué a las personas 
comunes de Chile y su metafísica. Y las hallé. Las raíces europeas comunes también me han sorprendido mucho. Me llamo a mí mismo un "cosmopolaco". En Chile sería un "cosmochileno" o, como tú dices, un "panamericano".

Sepúlveda: ¿Qué proyectos tienes actualmente? ¿Podrías hablar un poco sobre tu trabajo actual y tus intereses temáticos?

Becker: Por el momento tengo dos novelas que serán publicadas en Alemania. Te doy sus títulos en inglés: The Immortal Mr. Lindley [El inmortal Sr. Lindley] e Urge to the East [Impulso hacia el Este]. Una es una novela irónica sobre los problemas de identidad europeos y la otra una novela ambientada entre 1945 y hoy, y nuestra urgencia de libertad, también en un sentido negativo, por supuesto, contra el trasfondo de la difícil historia de Alemania en el siglo XX. Me interesan las corrientes filosóficas, psicológicas e históricas concretas; es por eso que mis personajes hablan como en las novelas de Issac B. Singer.

En Polonia será publicado mi ensayo "Cosmo-Polonia y Cosmopolaco: En búsqueda de un hogar europeo" y preparo tanto para Alemania como para Polonia mi nuevo poemario: Bartel y Gustabalda, una suerte de conversación con nuestros dioses y diablos, pero muy concretamente anclado en mi biografía y en la historia de Europa y el mundo.

Pero ahora estoy trabajando en una novela infantil porque siempre he querido describir un centro recreacional socialista para los trabajadores y directores de empresas, doctores y actores: una pequeña locación a orillas del lago que es el escenario mundial. Bueno, también terminé el poemario en polaco Detrás 


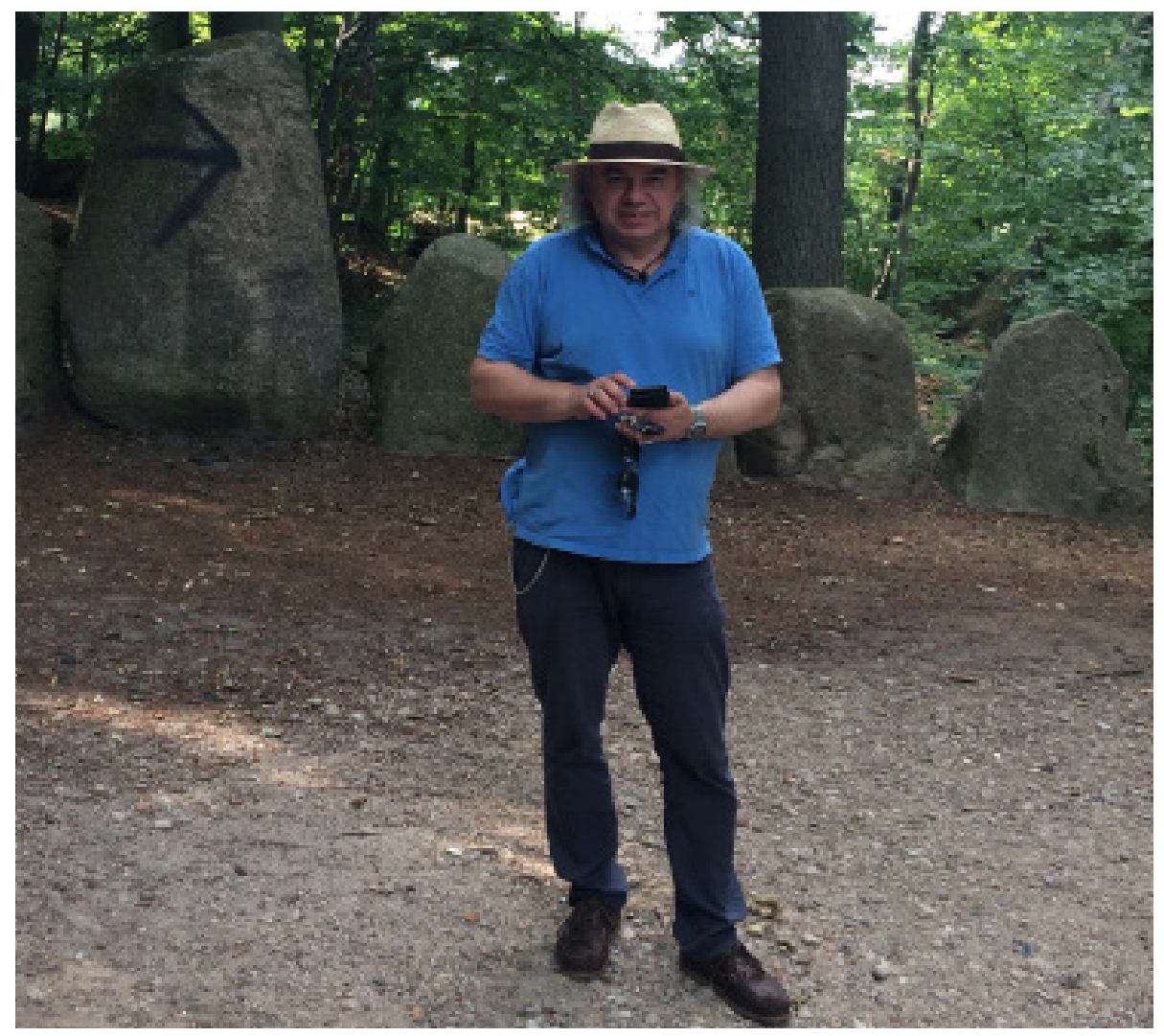

de las Columnas de Hércules. Estoy solo interesado en lo que hay detrás de esas columnas. No solo en Chile, América, la Atlántida, ¿qué hay allí, donde tal vez tengamos un origen común y cómo uno puede describir ese logos? ¿Dónde está ese lugar inefable? Quizás no lo veamos porque en realidad está en nosotros mismos como un par de anteojos que buscamos y que llevamos puestos sin que nos demos cuenta...

Agosto-septiembre de 2018 